\title{
The Pre-Evaluation of Crosslinked Anion Exchange (CAX) Resin on Nitrates Removal
}

\author{
A.A. Kassim ${ }^{1}$, N. Abdullah1, ${ }^{*}$ and M.Z. Yahya ${ }^{1}$ \\ ${ }^{1}$ Faculty of Chemical and Process Engineering Technology, Universiti Malaysia Pahang, 26300 Gambang, Pahang, Malaysia.
}

\begin{abstract}
This study is present the result of synthesizing crosslinked anion exchange (CAX) resin bearing quaternary ammonium functionalities. Crosslinked anion exchange of poly(HEMAco-EGDMA-co-VBC) were synthesized via the modified suspension polymerization technique, then treated in hyper-crosslinking reaction to increase specific surface area (SSA) of CAX beads resin from $\sim 5$ to $124 \mathrm{~m} 2 / \mathrm{g}$ and followed by amination treatment with $\mathrm{N}, \mathrm{N}$-dimethylbutylaminee (DMBA) to obtain CAX resin. After functionalized process, the amount of nitrogen content increased and intensity at $1265 \mathrm{~cm}^{-1}$ that assigned for chloromethyl group has decreased, showing that DMBA successfully being attached to the backbone. CAX resin was fully characterized by using Scanning Electron Microscopy (SEM), and Fourier Transform Infrared Spectroscopy (FT-IR) respectively. A pre-evaluation study was carried to investigate the performance of CAX beads resin to remove nitrate by using ion exchange method. Three parameters were used to study the sorption process; contact time, influent concentration and amount of resin used. For overall sorption, the sorption managed to obtain $88 \%$ nitrate removal by using $0.5 \mathrm{~g}$ of CAX resin at $50 \mathrm{ppm}$ influent concentration within 1-hour contact time and the highest adsorption of CAX achieved was $93 \%$ removal of nitrate ions within 4-hours contact time.
\end{abstract}

\section{KEYWORDS}

Anion exchange resin

Adsorption

Polymerization

\section{INTRODUCTION}

Water is widely used for various kind of reasons in many industries such as food and beverage, pharmaceutical, textiles, petroleum and agriculture industry. It is compulsory for each of the industry to treat their discharged water according to government's laws and standards. A clean treated water is one of the mandatory requirements not only for mankind demand but also for balancing the ecosystem. In fact, a good water body must be safe in terms of chemically, biologically and physically before it is being discharged to the nearby river. In spite of turbidity, harmful germs and bacteria becoming a major trait that need to be controlled for maintaining the quality standard of discharged water, removing contaminant ions such as nitrate is one of the biggest issues that has been concerned nowadays. As stated by World Hellth Organization (WHO), the standard ion intakes for nitrate must not more than $45 \mathrm{mg} / \mathrm{L}$ (Pintar et al., 2001). Excessive amount of nitrate in drinking water will contribute adverse effects on health such as methemoglobinemia (babyblue syndrome), rectal and colon cancer, and digestive organs failure (Samatya et al., 2006; Kim et al., 2015). Besides, inappropriate amount of nitrate present in the water body will damage the biodiversity where eutrophication problem will be occurred (Pintar et al., 2001). For this particular reason, biological denitrification, enzyme and catalytic reduction, reverse osmosis, electro-dialysis, bio-filtration and coagulation are some of notable examples method that have been introduced by previous researchers to eradicate ion contamination from water (Pintar et al., 2001; Smatya et al., 2006; Matos et al., 2008; Song et al., 2012; Song et al., 2012; Kim et al., 2015; Weinertova et al., 2017). However, some problematic issues rose since certain of these methods are non-environmentally friendly and obligating another extensive special treatment which lead to high capital and energy cost (Alighardashi et al., 2018). In this respect, it is worthwhile to consider not only the capital and effectiveness of the process but the chosen method must be appropriate to the local circumstances respectively (Barakat, 2011).

A consensus view has indicated that ion exchange may be very useful and show a great effectiveness to remove selectively contaminants by using an adsorbent as a medium to exchange ion (Haki et al., 2016). Novel of researches have been devoted to understand the process by implying the concept of ion exchange method in many industry cases. Eventually, it accentuates the realization that the ion exchange method it a simple, environmentally friendly, low-cost maintenance, convenient and also a low capital process (Eipztein et al., 2015; Alighardashi et al., 2018). Moreover, this method shows a remarkable result since it also able to remove contaminant ions quantitatively, less sensitivity toward $\mathrm{pH}$ during the treatment process and the adsorbent also have a long lifespan (Kim et al., 2004).

Previously, ion exchange method can be done by using a selected base-sorbent such as silica, carbon and polymer (Subri et al., 2017). However, silica and carbon base-sorbent have showed weaknesses in the systems due to lacking in term of permeability, thermodynamically and mechanical stability (Larous et al., 2018; Fontanal et al., 2018). Davankov and his co-workers had introduced hyper-crosslinked (H-XL) polymer to overcome all these problems (Davankov et al., 
1989; Davankov et al., 1990; Davankov et al., 1996b; Davankov et al., 2002). These polymer particles can be classified into three different size classes such as macro- $(>50 \mathrm{~nm})$, meso- $(50-2 \mathrm{~nm})$ and microporous $(<2 \mathrm{~nm})($ Gokmen and Prez, 2012). One of the greatest benefits of H-XL resin is it can provide a high specific surface area (SSA) due to its porosity (Fritz, 1995). Though, different precursors gave different value of SSA through hyper-crosslinking reaction. Subri et al. (2017) found that hyper-crosslinking process of precursor particles from acrylonitrile (AN), divinylbenzene (DVB) and vinyl benzyl chloride (VBC) could achieved SSA up to $1078 \mathrm{~m}^{2} \mathrm{~g}^{-1}$ with $4.0 \mathrm{~nm}$ of maximum pore size. Fontanal and his co-workers (2015) also managed to obtained SSA up to $1125 \mathrm{~m}^{2} \mathrm{~g}^{-1}$ by hyper-crosslinking precursors particles from methacrylic acid (MMA), DVB and VBC. Paulino and Afonso (2012) supported the claimed that the development of SSA of porous polymer particles not only could increase the performance in sorption process but also in separation on rare earth elements (Fritz, 1995). Previous studies had indicated that the presence of hydrophobicity in the adsorbent would affect the sorption process (Song et al., 2012; Song et al., 2012; Paulino et al., 2012; Wu et al., 2013; Sun et al., 2015). This hydrophobicity is more efficient in the retention of non-polar compounds than the retention of polar compounds. Therefore, development of hydrophilic bead particles can provide alternative adsorbent for any applications involving polar compound.

In this study, the optimized crosslinked anion exchange (CAX) resin was developed by using hydroethylmethacrylate (HEMA) as monomer with vinylbenzyl chloride (VBC) as a co-monomer and ethylene glycol dimethacrylate (EGDMA) as a cross-linker. This study attempted to address the issue of preparing high content of chloro-methyl functional group at polymeric precursor backbone whilst still maintaining the quality of precursor. High SSA of H-XL poly (HEMA-coVBC-co-EDGMA) was achieved using hyper-crosslinking reaction by exploiting pendant chloromethyl group as electrophile source where the reaction was maintaned for 18 hours to allow maximum adsorption of the solvent into the polymer matrix. Furthermore, in view toward application, the H-XL polymer will be functionalized. The functionalization process will be involved amination process by attaching quaternary ammonium into the polymeric backbone thus turning the hydrophilic H-XL polymer into a strong anion exchange resin - CAX respectively. Same method as purposed by Norhayati et al. (2019) to carry a pre-evaluation test on CAX resin. This study was conducted to investigate CAX performance to adsorb nitrate ions from water body. The investigation was carried under three parameters by varying the influent concentration, CAX dosage and the interaction time between the adsorbent and solution

\section{EXPERIMENTAL}

\section{Chemicals and Materials}

For precursor polymer, the reagents used were same in the previous study (Yahya et al., 2017). All chemicals such as benzoyl peroxide (BPO) (75\%), poly( $N$-vinylpyrrolidone) 55 (PVP), (98\%), 4-vinylbenzyl chloride (VBC) (97\%), ethylene glycol dimethacrylate (EGDMA) and 2-hydroethylmethacrylate (HEMA) (97\%) were obtained from Sigma Aldrich. Methanol and chloroform were used to purify these chemical excluding BPO, EGDMA and HEMA that purified thoroughly by using aluminum oxide.

In the hyper-crosslinking reaction, nitric acid (HNO3) with 65\% concentration, 1.2-Dicholoroethane (DCE) (99\%) and iron (III) chloride $\left(\mathrm{FeCl}_{3}\right)(98 \%)$ were purchased from R\&M Chemical. While methanol and 1.2-Dicholoroethane (DCE) were acquired from Sigma Aldrich.

The reagents that were being used in the synthesis of super crosslinked anion exchange resin polymer were sodium bicarbonate (99.7\%) and N, N-Dimethyl butylamine (DMBA) (99.8\%). All the chemicals were supplied by SigmaAldrich.

Meanwhile, for pre-evaluation resin, the synthesized CAX resin was used during the adsorption process. While other materials such as sodium hydroxide $(\mathrm{NaOH})$ was supplied from Sigma Aldrich $(99 \%)$. The nitrate stock solution used in this study was prepared by dissolving an accurate quantity of $\mathrm{NaNO}_{3}(97 \%)$ obtained from Sigma Aldrich with deionized water that was acquired by using Elix ${ }^{\circledR}$ Essential 5 UV Water Purification System from Merck Milipore. A range of dilutions, 20-200 mg/L, were prepared respectively. The $\mathrm{pH}$ of the aqueous solutions of $\mathrm{NO}_{3}$ was approximately 6.7 and did not change significantly with the dilution.

\section{Poly(HEMA-co-EGDMA-co-VBC) Precursor Synthesis}

In this step, a modified suspension polymerization is used to produce macro-size beads particles. This study was done previously where a continuous phase was prepared by mixing PVP (2-4 wt \% of monomer feed) within solvent and distilled water (Yahya et al., 2017). Organic phase was prepared by mixing toluene, HEMA, EGDMA, PVP and benzoyl peroxide (3 $\mathrm{wt} \%$ of monomer feed) together. The mixture then being stirred until homogenous solution formed. The organic phase then being relocated into $250 \mathrm{~mL}$ four neck round-bottomed flask with magnetic stirrer and stirred at constant rate at $300 \mathrm{rpm}$. After half an hour, VBC was added to the mixture. The reactor was flushed by nitrogen thoroughly the experiments with a set temperature at $75{ }^{\circ} \mathrm{C}$ for 6 hours. The produced macro-spheres were washed by distilled water and ethyl alcohol before dry in $60^{\circ} \mathrm{C}$ for 24 hours (Yahya et al., 2017).

\section{Hyper-crosslinked Poly (HEMA-co-EGDMA-co-VBC) Resin Synthesis}

Hyper-crosslinking reaction method was based on previous reported methods (Bratkowska et al., 2010b; Fontanals et al., 2014). 1, 2-dichloroethane (DCE) was mixed with $10 \mathrm{~g}$ synthesized macro-sphere precursor in a flask for 1-hour at room temperature with constant inlet of nitrogen gas until the mixture was fully swelled. Then, the reaction was proceeded by adding 1:1 molar ration of $\mathrm{FeCl}_{3}$ and the mixture was heated to $80^{\circ} \mathrm{C}$ for 18 hours where new particulates known as 
H-XL were discovered. These particulates were filtered and washed by using $\mathrm{HNO}_{3}$ and methanol. A Soxhlet extractor was used to extracted the $\mathrm{H}-\mathrm{XL}$ particles and dried at $50^{\circ} \mathrm{C}$.

\section{Crosslinked Anion Exchange (CAX) Resin Synthesis}

$5 \mathrm{~g}$ of H-XL polymer and $100 \mathrm{~mL}$ dried toluene were placed in a round-bottomed flask $(250 \mathrm{~mL})$, and the mixture was left under nitrogen for 1 hour to wet the beads. Then, DMBA (in 2 to 7.5 molar excess relative to $-\mathrm{CH}_{2} \mathrm{Cl}$ ) was added to the solution. The mixture was then rapidly heated at $80{ }^{\circ} \mathrm{C}$ and kept at this temperature for 18 hours. The CAX particles were filtered and washed with toluene, methanol and then washed several times with aqueous 5\% (w/v) sodium bicarbonate and water. They were then extracted overnight with acetone in a Soxhlet extractor before drying overnight in the oven at $40{ }^{\circ} \mathrm{C}$ (Fontanal et al., 2008c).

\section{Pre-Evaluation Experiments of CAX Resin}

The resins were equilibrated using $500 \mathrm{~mL}$ of $1 \mathrm{~mol} / \mathrm{L} \mathrm{NaOH}$ for 30 minutes. The resin then drained two times out from the column using pure water. All the experiments were conducted in a batch system under Solid Phase Extraction (SPE) method for CAX resins. The experiments were conducted in a room temperature by contacting the resin with nitrates solution in the column where the resins were spiked with certain volume of nitrates standard solution directly. For the first parameter, the resins at $0.5 \mathrm{~cm}$ bed length was contacted with $20 \mathrm{~mL}$ of nitrates solution with different concentration at 20,50,100 and $200 \mathrm{ppm}$ respectively for 1 hour to study the effect of initial concentrations of nitrates solution toward the resins. The second parameter was to study the effect of the adsorption capacity of the resins at different bed length of resin. The resins were varied at different bed length $(0.5,1.0,1.5$ and $2.0 \mathrm{~cm})$ inside the column contacted with 50 ppm of nitrates water for 1 hour. Lastly, the effect of contact time (1, 2, 3 and 4 hour) between the resins and the $50 \mathrm{ppm}$ of nitrates solution at $0.5 \mathrm{~cm}$ bed length resin were studied in detailed.

\section{Determination of nitrate removal efficient}

The nitrate adsorption efficiency can be calculated by using Equation (1) below:

$$
\text { Nitrate Removal Efficiency }=\frac{\left(C_{i}-C_{f}\right)}{C_{i}} \times 100 \%
$$

Where, $\mathrm{C}_{\mathrm{i}}$ indicates the influent concentration of nitrate ion $(\mathrm{mg} / \mathrm{L})$ and $\mathrm{C}_{\mathrm{f}}$ denotes as effluent concentration of the solution after the experiment (Zheng et al., 2010). Equation (2) shows the formula on how much nitrate ion (mg/g) adsorbed during the process

$$
\text { Adsorption Amount }=\frac{\left(C_{i}-C_{f}\right)}{m} \times V
$$

Where, the $\mathrm{m}$ and $\mathrm{V}$ denote as mass of CAX resin used and volume of synthetic solution present during the experiments (L), respectively (Song et al., 2016).

\section{Particle Characterization}

Scanning Electron Microscopy (SEM, Brunauer-Emmett-Teller (BET) and Fourier Transforms Infrared Spectroscopy Analysis (FT-IR) analysis were used to characterize the resin particles in this study. First, SEM analysis were executed onto the resin particle to analyze the morphology and surface structure by using Unit JOEL.JSM- 7800F model. The analysis was carried out at a condition of 20X, and 50X magnifications. BET analysis was used to identify the specific surface area (SSA) on the evaluation of CAX resin where the particles would be degassed up to $300{ }^{\circ} \mathrm{C}$ for an overnight to remove moisture content before SSA were taken. Meanwhile, FT-IR analysis is used to identify the functional group presence in the particles by using Spherical Diamond ATR Nicolet iS50 (Thermo Scientific) provided by Chemical Engineering Laboratory, Universiti of Malaysia Pahang. Each of the sample spectrum was scanned with a resolution of 4 $\mathrm{cm}^{-1}$; an average of 32 scans thoroughly.

\section{EXPERIMENTAL RESULTS}

\section{The Comparison of Morphology and Specific Surface Area (SSA)}

Crosslinked anion exchange (CAX) beads were successfully derived from the precursor of poly(HEMA-co-EGDMA$c o-\mathrm{VBC})$ then treated in hyper-crosslinking $(\mathrm{H}-\mathrm{XL})$ reaction and followed by treatment with dimethylbutylaminee (DMBA) to obtain CAX. Figure 1a, 1b, and 1c show the SEM images of poly(HEMA-co-EGDMA-co-VBC) precursor, $\mathrm{H}-\mathrm{XL}$ polymer and CAX resin respectively. The particles managed to retain its shape even after hyper-crosslinking reaction (Figure 1b). During the hyper-crosslinking reaction, it was reported by other researchers that some of the microspheres were damaged due to the abrupt changes in swelling and collapse after drying (Kesenci et al., 1996). However, the amount of crosslinker was essential to retain the shape of microsphere even after hyper-crosslinking reaction; the more amount of crosslinker attached to the microspheres the more capable the microspheres to retain its shape (Davankov et al., 1989). 
For this case, the majority of the microspheres managed to retain their shape after hyper-crosslinking reaction via suspension polymerization. However, cracks can be observed on the surface in some of the microspheres (Figure 1b). The cracks may be occurred due to extra rigidity provided by the high amount of crosslinker. During hyper-crosslinking reaction, the microspheres were abruptly swelling outward while crosslinker trying to retain the shape of microspheres. The result of the clash between these two forces caused the cracked to occur at the surface of the microspheres. There were no significant changes in the particle's morphology after amination reaction (Figure 1c). The particles managed to retain its shape after amination reaction. The CAX's surface became smoother and the pore which were prominent at the surface of H-XL polymer became less prominent at the surface of the CAX resin (Figure 1c). This might be caused by high amount of DMBA blocking the pores of the particles.

Usually, small pore size would increase the surface area of beads resin. . But in this case, the pore size of precursor, $\mathrm{H}-\mathrm{XL}$ and CAX particles also decreased at $1.950,0.403$ and $0.354 \mathrm{~nm}$ by giving the BET SSA at 5,124 and $27 \mathrm{~m}^{2} / \mathrm{g}$, respectively. The amount of surface area per gram depends on the availability of the pores present in the beads. As discussed morphology from the Figure 1, it is clearly been seen that the surface of CAX resin is smoother compared to precursor and H-XL beads. Table 1 evidently shows that the pore volume also increases in sequence from precursor $<$ $\mathrm{CAX}<\mathrm{H}-\mathrm{XL}$ The presence of pores in the CAX resin is smaller thus it will lead to the calculated surface area become lesser.

Upon hyper-crosslinking reaction, the SSA of H-XL particles managed to obtained higher than precursor's SSA upto $124 \mathrm{~m}^{2} / \mathrm{g}$ after hyper-crosslinking reaction. Increasing the SSA of precursor particles were contributed to the increasing number of pores due to the formation of methylene bridge during hyper-crosslinking reactions (Bratkowska et al., 2010b; Fontanals et al., 2014). However, the BET analysis showed that the SSA of CAX resin was lesser than H-XL particles at 27 and $124 \mathrm{~m}^{2} / \mathrm{g}$ accordingly. Adding DMBA reduced the SSA of the particles resin. This fact resulting the SSA of CAX decreased compared to H-XL polymer.

Table 1. Comparison of SSA of the precursor, H-XL and CAX

\begin{tabular}{cccc}
\hline Sample & Pore Volume $\left(\mathrm{cm}^{3} / \mathrm{g}\right)$ & Pore Size $(\mathrm{nm})$ & BET SSA $\left(\mathrm{m}^{2} / \mathrm{g}\right)$ \\
\hline Precursor & 0.000983 & 1.950 & $\sim 5$ \\
H-XL & 0.0125 & 0.403 & 124 \\
CAX & 0.002392 & 0.354 & 27 \\
\hline
\end{tabular}
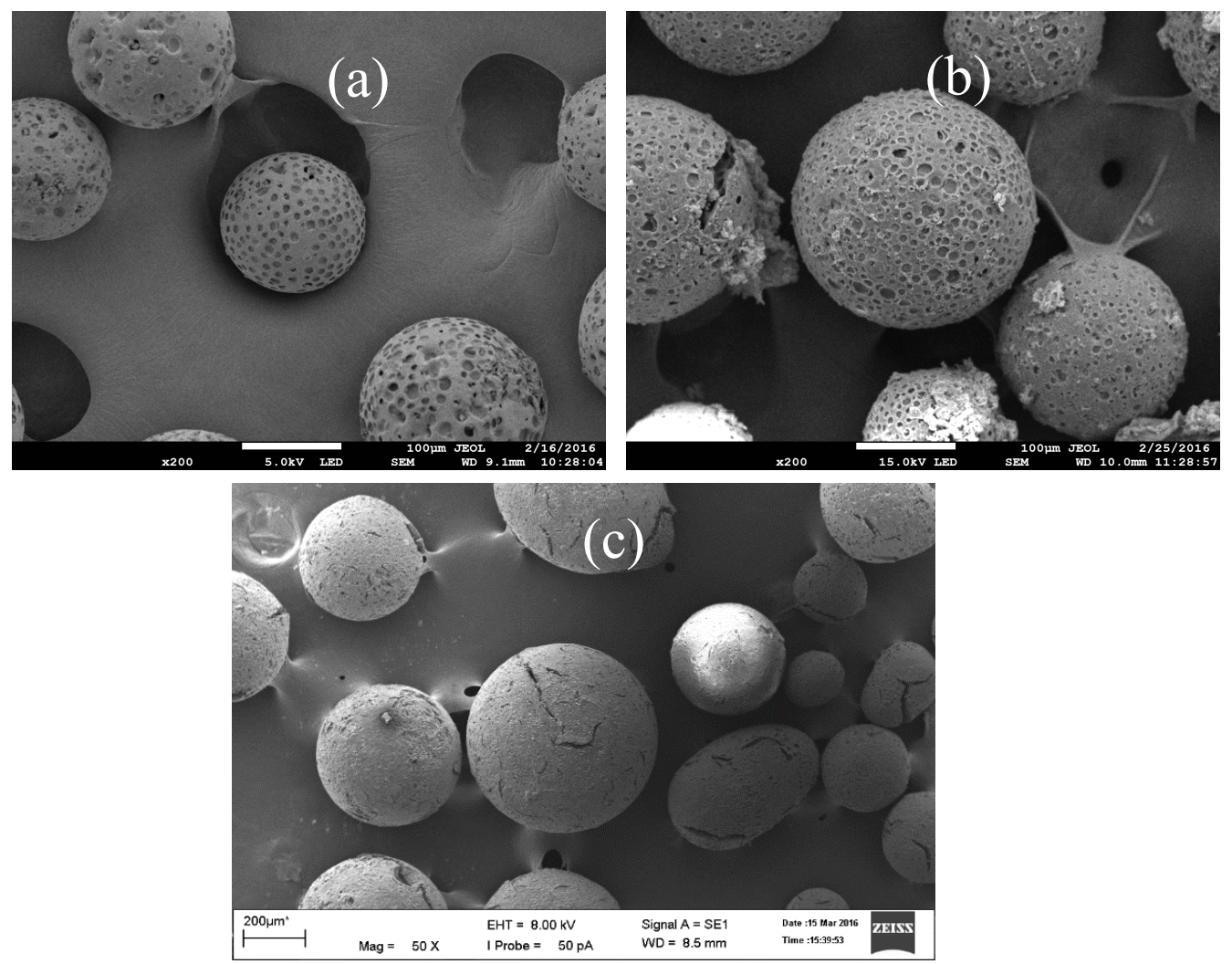

Figure 1. SEM images at (a) precursor, (b) H-XL (c) CAX resin 


\section{FT-IR Analysis}

The structure in polymer backbone for precursor, H-XL and CAX resin can be observed through FT-IR spectra (Figure 2). Overall, the existence of broad band at the region of $\sim 3500 \mathrm{~cm}^{-1}$ showed the characteristic of hydroxyl group inside the HEMA molecule (Kesenci et al., 1996; Kumar et al., 2008). A sharp band at $1718 \mathrm{~cm}^{-1}$ indicates the existence of carbonyl group inside the particles arises from EGDMA (Soykan et al., 2007). While significant band at $\sim 1265 \mathrm{~cm}^{-1}$, indicates the characteristic of the chloromethyl $\left(\mathrm{CH}_{2} \mathrm{Cl}\right)$ group (Bratkowska et al., 2010a). From Figure 2, the characteristics of absorption bands at $1265 \mathrm{~cm}^{-1}$ and $670 \mathrm{~cm}^{-1}$ arise from stretching vibrations of C-Cl bonds. Both bands $\left(1265 \mathrm{~cm}^{-1}\right.$ and $\left.670 \mathrm{~cm}^{-1}\right)$ intensity reduced or diminished after hyper-crosslinking reaction and further reduced after amination reaction. This was consistent with displacement of chloride to form methylene bridge in hyper-crosslinking reaction and formation of quaternary ammonium functional group in amination process (Fontanals et al., 2014). Introduction of DMBA in the amination reaction into the surface of the particles will increase the intensity of $-\mathrm{CH}_{3}$ and $\mathrm{CH}_{2}$ band in the FT-IR spectra. The increasing intensity of $1383 \mathrm{~cm}^{-1}$ peak at CAX resin spectra indicates that more $-\mathrm{CH}_{3}$ in the backbone originated from DMBA molecules. The same observation can also be identified in the $1450 \mathrm{~cm}^{-1}$ peak which indicates the presence of $-\mathrm{CH}_{2}$ vibrations. After amination reaction, the intensity of $1450 \mathrm{~cm}^{-1}$ increased. Thus, it indicated that DMBA was successfully installed in the backbone resin.

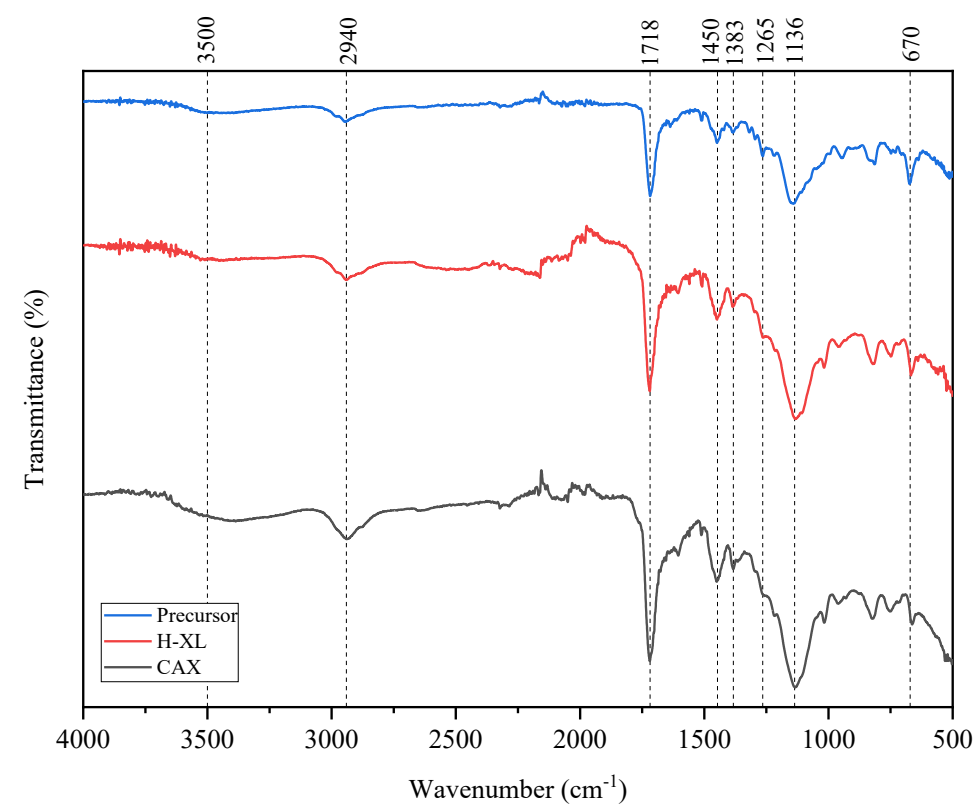

Figure 2. FT-IR spectra for precursor, H-XL and CAX

\section{Pre-evaluation of CAX Resin}

\section{Effect of different bed resin}

Figure 3 shows the trend of CAX resin onto the efficiency of nitrates removal from the waste water solution. Generally, nitrate adsorption increased steadily with the rising capacity of bed resin. At $0.5 \mathrm{~cm}$ of bed resin, CAX resin managed to adsorb nitrate ion approximately at $78 \%$. In 1.0 and $1.5 \mathrm{~cm}$ of bed resin, the adsorption capacity of CAX resin shown at 80 and $84 \%$ respectively. The bulk sorption at final bed length of resin $(2.0 \mathrm{~cm})$ was $89 \%$ of nitrate removal. According to Kalaruban et al. (2016), the elevated adsorbent dose caused the removal efficiency increased. This is due to increase in the number of adsorption sites. High dose adsorbent will increase the surface contacting area, hence the positive charge present in the particle site will rose too. Thus, it will trap the negatively charge ion more than lower dose adsorbent. The adsorption amount $(\mathrm{mg} / \mathrm{g})$ showed an opposite trend. As the adsorbent increased, the adsorption amount would decrease significantly because both of them have an inverse relationship as demonstrated in the aforementioned equation respectively (Equation 2). 


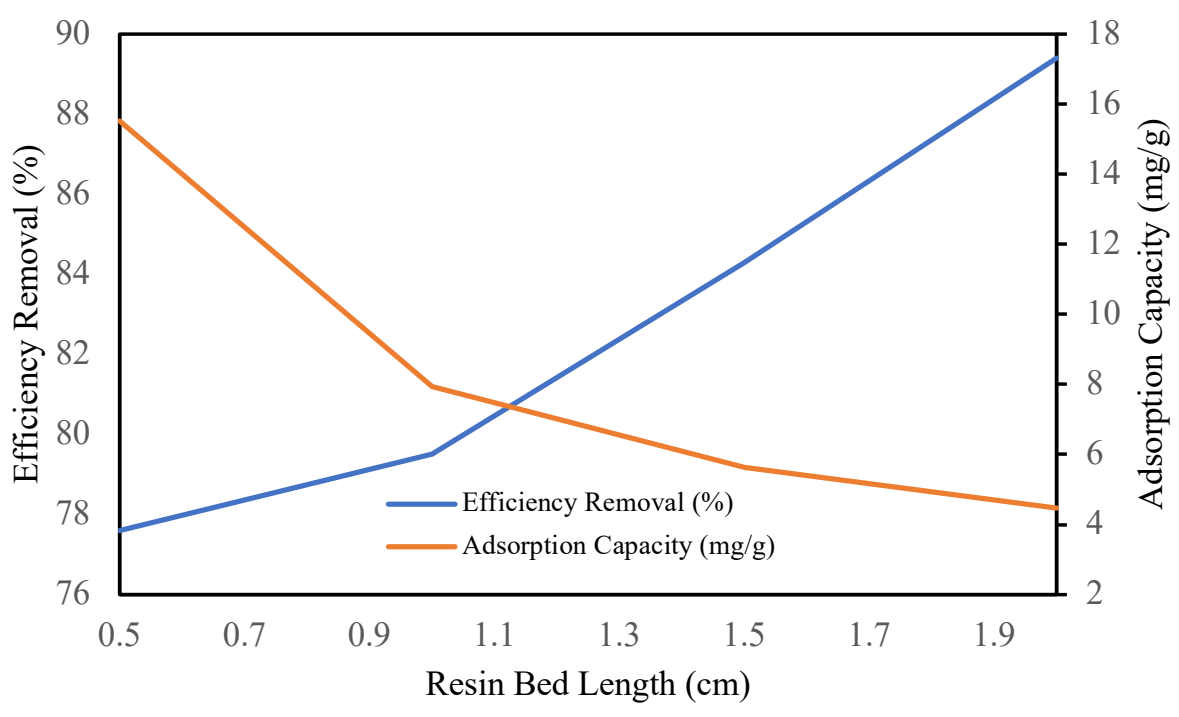

Figure 3. The efficiency of nitrates removal at different length of bed resins with $50 \mathrm{ppm}$ of nitrates influent concentration in 1-hour contact time.

\section{Effect of initial concentration of nitrate solution}

Different amount of influent of waste water solution would give different of performances of the nitrate ions removal [3]. From Figure 4, as the other parameters were kept constant during the experiments such as the resin dosage used and one-hour contact time between resin and solution, the removal efficiency of nitrate ion declined linearly as the concentration of the solution increased at $20,50,100$ and $200 \mathrm{mg} / \mathrm{L}$ respectively. The experiments were fixed by using $0.5 \mathrm{~cm}$ bed length of CAX resin so the sorption capacity could not be guarantee to achieve high removal of nitrate from the solution. From Fig. 4, it was illustrated that the percentage of nitrate removal has decreased from $90 \%$ to $74 \%$ as the concentration influent increased from 20 to $200 \mathrm{mg} / \mathrm{L}$ respectively. Nevertheless, the amount of nitrate ion being adsorbed increased from 7.2 to $59.2 \mathrm{mg} / \mathrm{g}$. According to Raji et al. (2013), the efficiency of sorption process depends on the initial concentration of influent. When the concentration too high, there would become abundant of nitrates ion as the solution pass through the column, the active positive site would become lack and could not trapped the remaining anions thus it will decrease the performance of removing ions effectively

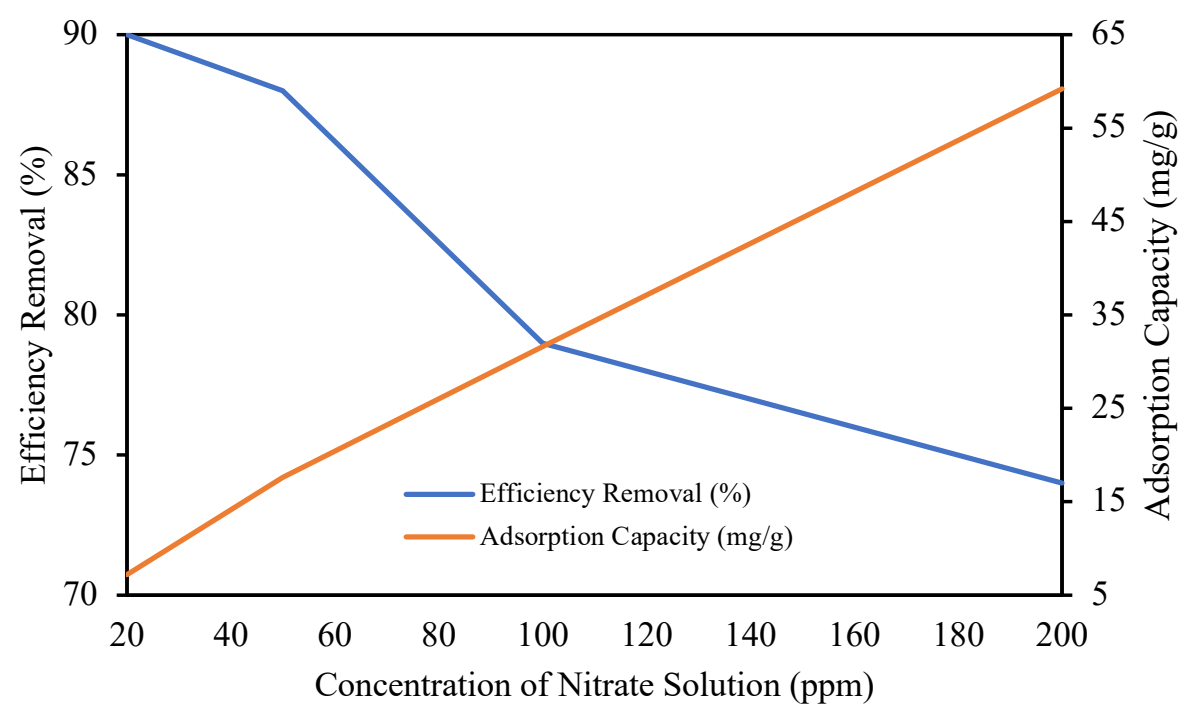

Figure 4. The efficiency of nitrates removal at different concentration of influent in $0.5 \mathrm{~cm}$ of bed resin and 1-hour contact time.

\section{Effect of different contact time}

As mentioned by Samatya et al. and Raji et al., the higher the contact time between the resin and the solution the higher the efficiency of removal of ion (Samatya et al., 2016; Kalaruban et al., 2016). This can be testified by referring to Figure 5 showed the trending graph of CAX resin ascending almost linearly as the contact time increased. In 1 hours contact time, the efficiency of nitrate removal for CAX resin was $88 \%$. But the removal efficiency kept increasing until the efficiency managed to achieve equilibrium at $93 \%$ for 4 hours of contact time. The adsorption amount of nitrate ions 
also increased from 17.6 to $18.6 \mathrm{mg} / \mathrm{g}$ at 1 to 4 hours contact time of influent and the resin respectively. The contact time between the resin and the solution allowed the ion transfer between them could be occurred. For 1 hour, the ions were barely contacted with the resin as the column probably has its own deficiency. Therefore, the more hours are allowable to be contact between the resins and the synthetic waste water, the higher of nitrates ion could be separated from the influent solution.

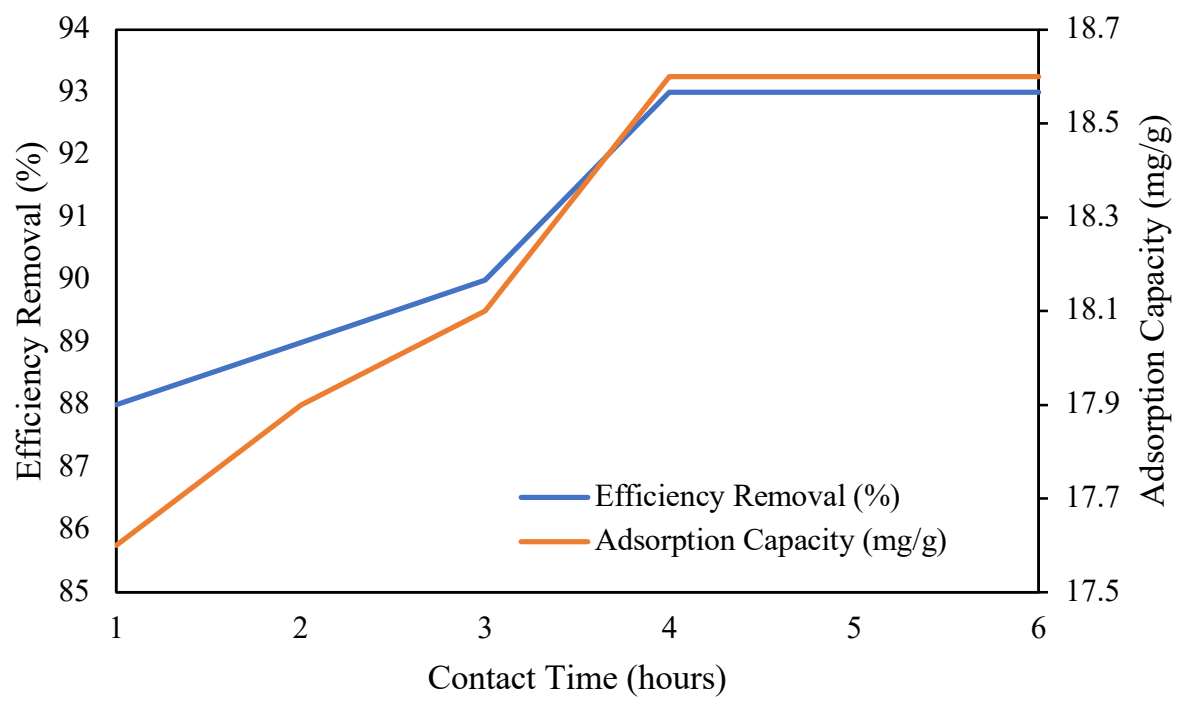

Figure 5. The efficiency of nitrates removal at different contact time with $50 \mathrm{ppm}$ of nitrates influent concentration in $0.5 \mathrm{~cm}$ of bed resin

\section{CONCLUSION}

As a conclusion, the synthesis of CAX resin could be obtained through three steps process; suspension polymerization of precursor, proceeded by hyper-crosslinking reaction then followed by amination process to form strong crosslinked anion resin. From the study, the morphology of particles has changed from pores-rough surface to smooth-clean surface due to the addition of DMBA in the amination process. In hyper-crosslinking reaction, the specific surface area (SSA) has increased to $124 \mathrm{~m}^{2} \mathrm{~g}^{-1}$ but later become lesser in amination process at $27 \mathrm{~m}^{2} \mathrm{~g}^{-1}$ respectively. The FT-IR analysis showed that all the crosslinker managed to be implemented and remained in the back-bond particles throughout these reaction processes. After functionalized process, $1265 \mathrm{~cm}^{-1}$ that assigned for chloromethyl group decrease, and both $-\mathrm{CH}_{2}$ and $-\mathrm{CH}_{3}$ band increased; showing that DMBA successfully being attached to the backbone. A pre-evaluation study by using CAX resin to remove nitrate ions from waste water solution was effectively investigated. At 1-hour contacted time, CAX resin already managed to remove $75 \%$ of nitrate ions from the influent solution. The highest adsorption of nitrate ion obtained was $93 \%$ at 4 hours contacted time by using only $0.5 \mathrm{~g}$ of CAX resin. Thus, it shows that CAX resin can be one of the promising resins; however, the CAX resin still needed to be investigated into more broad parameters so the optimum condition can be implemented to remove contaminated ions efficiently.

\section{ACKNOWLEDGMENT}

The authors would like to thank University of Malaysia Pahang for excellent laboratory facilities and providing financial support to buy chemicals and materials under grants RDU170323 and RDU180317.

\section{REFERENCES}

Alighardashi, A., Kashitarash Esfahani, Z., Najafi, F., Afkhami, A., and Hassani, N. (2018). Development and application of graphene oxide/poly-amidoamines dendrimers (go/pamams) nano-composite for nitrate removal from aqueous solutions. Environmental Processes. 5(1), 41-64.

Barakat, M. (2011). New trends in removing heavy metals from industrial wastewater. Arabian Journal of Chemistry, 4(4), 361-377.

Bratkowska, D., Fontanals, N., Borrull, F., Cormack, P., Sherrington, D. and Marcé, R. (2010a). Hydrophilic hypercrosslinked polymeric sorbents for the solid-phase extraction of polar contaminants from water. Journal of Chromatography A. 1217, 32383243

Davankov, V. and Tsyurupa, M. P. (1989). Structure and properties of porous hypercrosslinked polystyrene sorbents styrosorb. Pure and Applied Chemistry. 61, 1881-1888.

Davankov, V. A. and Tsyurupa, M. P. (1990). Structure and properties of hypercrosslinked polystyrene- the first representative of a new class of polymer networks. Reactive Polymers. 13, 27-42.

Davankov, V. A., Ilyin, M. M., Tsyurupa, M. P., Timofeeva, G. I. and Dubrovina, L. V. (1996b). From a dissolved polystyrene coil to 
an intramolecularly-hyper-cross-linked "nanosponge". Macromolecules. 29, 8398-8403.

Davankov, V., Tsyurupa, M., Ilyin, M. and Pavlova, L. (2002). Hypercross-linked polystyrene and its potentials for liquid chromatography: a mini-review. Journal of Chromatography A. 965, 65-73.

Epsztein, R., Nir, O., Lahav, O., and Green, M. (2015). Selective nitrate removal from groundwater using a hybrid nanofiltrationreverse osmosis filtration scheme. Chemical Engineering Journal. 279, 372-378.

Fontanals, N., Marcé, R., Borrull, F. and Cormack, P. (2015). Hypercrosslinked materials: preparation, characterisation and applications. Polymer Chemistry. 6, 7231-7244.

Fontanals, N., Marcé, R. M., Cormack, P. A., Sherrington, D. C. and Borrull, F. (2008c). Monodisperse, hypercrosslinked polymer microspheres as tailor-made sorbents for highly efficient solid-phase extractions of polar pollutants from water samples. Journal of Chromatography A. 1191, 118-124.

Fontanals, N., Miralles, N., Abdullah, N., Davies, A., Gilart, N. and Cormack, P. (2014). Evaluation of strong cation-exchange polymers for the determination of drugs by solid-phase extraction-liquid chromatography-tandem mass spectrometry. Journal of Chromatography A. 1343, 55-62.

Fritz, J. S., Dumont, P. J. and Schmidt, L. W. (1995). Methods and materials for solid-phase extraction. Journal of Chromatography A. 691, 133-140.

Gokmen, M. T. and Du Prez, F. E. (2012). Porous polymer particles-A comprehensive guide to synthesis, characterization, functionalization and applications. Progress in Polymer Science. 37, 365-405.

Haki, M., Laabd, M., Chafai, H., Kabli, H., Ez-zahery, M., Bazzaoui, M., ... Albourine, A. (2016). Comparative adsorption of nitrate ions on the polypyrrole and polyaniline from aqueous solution. Journal of Dispersion Science and Technology. 38(4), 598-603.

Kalaruban, M., Loganathan, P., Shim, W., Kandasamy, J., Naidu, G., Nguyen, T. V., and Vigneswaran, S. (2016). Removing nitrate from water using iron-modified Dowex $21 \mathrm{~K}$ XLT ion exchange resin: Batch and fluidised-bed adsorption studies. Separation and Purification Technology. 158, 62-70.

Kesenci, K., Tuncel, A. and Pişkin, E. (1996). Swellable ethylene glycol dimethacrylate-hydroxyethylmethacrylate copolymer beads. Reactive and Functional Polymers. 31, 137-147.

Kim, J., and Benjamin, M. M. (2004). Modeling a novel ion exchange process for arsenic and nitrate removal. Water Research. 38(8), 2053-2062.

Kim, Y. J., Lee, K., Cha, H. Y., Yoo, K. M., Jeon, C. S., Kim, H. J., . . Park, K. Y. (2015). Electrolytic denitrification with an ionexchange membrane in groundwater. Water Science and Technology: Water Supply. 15(6), 1320-1325.

Kumar, N. A., Ganapathy, H. S., Kim, J. S., Jeong, Y. S. \& Jeong, Y. T. 2008. Preparation of poly 2-hydroxyethyl methacrylate functionalized carbon nanotubes as novel biomaterial nanocomposites. European Polymer Journal. 44, 579-586.

Larous, S., and Meniai, A. (2016). Adsorption of Diclofenac from aqueous solution using activated carbon prepared from olive stones. International Journal of Hydrogen Energy. 41(24), 10380-10390.

Matos, C.T., Fortunato, R., Velizarov, S., Reis, M. A. M., and Crespo, J. G. (2008). Removal of mono-valent oxyanions from water in an ion exchange membrane bioreactor: influence of membrane perm selectivity. Water Res. 42,1785-1795.

Norhayati, A., Muhammad, R. and Kassim, A. A. (2019). Pre-evaluation of strong base anion exchange, amberlite ira 958-cl resin for nitrate removal. Materials Today: Proceedings. 17, 679-85.

Paulino, J. F. and Afonso, J. C. (2012). New strategies for treatment and reuse of spent sulfidic caustic stream from petroleum industry. Química Nova. 35, 1447-1452.

Pintar, A., Batista, J., and Levec, J. (2001). Integrated ion exchange/catalytic process for efficient removal of nitrates from drinking water. Chemical Engineering Science. 56(4), 1551-1559.

Raji, F., and Pakizeh, M. (2013). Study of Hg (II) species removal from aqueous solution using hybrid ZnCl2-MCM-41 adsorbent. Applied Surface Science. 282, 415-424.

Samatya, S., Kabay, N., Yüksel, Ü., Arda, M., and Yüksel, M. (2006). Removal of nitrate from aqueous solution by nitrate selective ion exchange resins. Reactive and Functional Polymers. 66(11), 1206-1214.

Song, H. O., Zhou, Y., Li, A. M. and Mueller, S. (2012). Selective removal of nitrate by using a novel macroporous acrylic anion exchange resin. Chinese Chemical Letter. 23, 603-606.

Song H, Zhou Y, Li A, and Mueller S. (2012). Selective removal of nitrate from water by a macroporous strong basic anion exchange resin. Desalination. 296,53-60.

Song, W., Gao, B., Xu, X., Wang, F., Xue, N., Sun, S., and Jia, R. (2016). Adsorption of nitrate from aqueous solution by magnetic amine-crosslinked biopolymer-based corn stalk and its chemical regeneration property. Journal of Hazardous Materials. 304, 280-290.

Soykan, C., Delibas, A. and Coskun, R. (2007). Copolymers of N-(4-bromophenyl)-2-methacrylamide with 2-hydroxyethyl methacrylate. Express Polymer Letters. 1, 594-603.

Subri, N. N., Cormack, P. A., Jamil, S. N., Abdullah, L. C., and Daik, R. (2017). Synthesis of poly(acrylonitrile-co-divinylbenzeneco-vinylbenzyl chloride)-derived hypercrosslinked polymer microspheres and a preliminary evaluation of their potential for the solid-phase capture of pharmaceuticals. Journal of Applied Polymer Science. 135(2), 45677

Sun, J., Li, X., Quan, Y., Yin, Y. and Zheng, S. (2015). Effect of long-term organic removal on ion exchange properties and performance during sewage tertiary treatment by conventional anion exchange resins. Chemosphere. 136, 181-189.

Weinertova, K., Honorato, R. S., Stranska, E., and Nedela, D. (2017). Comparison of heterogeneous anion-exchange membranes for nitrate ion removal from mixed salt solution. Chemical Papers. 72(2), 469-478.

Wu, W. L., Tan, Z. Q., Wu, G. J., Yuan, L., Zhu, W. L., Bao, Y. L., Pan, L. Y., Yang, Y. J. and Zheng, J. X. (2013). Deacidification of crude low-calorie cocoa butter with liquid-liquid extraction and strong-base anion exchange resin. Separation and Purification Technology. 102, 163-172.

Yahya, M. Z. and Abdullah, N. (2017). Preparation and Characterization of hypercrosslinked poly (HEMA-co-EGDMA-co-VBC). Indian Journal of Science and Technology. 8(1).

Zheng, Y. and Wang, A. (2010). Nitrate adsorption using poly (dimethyl diallyl ammonium chloride)/polyacrylamide hydrogel. Journal of Chemical \& Engineering Data. 55(9), 3494-3500. 